\title{
DETERMINANTS OF MANUFACTURING EFFICIENCY IN CANADIAN CITIES: A STOCHASTIC FRONTIER APPROACH
}

\author{
Kim McCoy and Ronald L. Moomaw*
}

\begin{abstract}
This study uses panel data to estimate stochastic production frontiers for Canadian cities. Efficiency indices are derived from the production frontiers. Regression analysis of the determinants of a city's inefficiency shows that population size and density both increase efficiency. These results are consistent with the existence of static agglomeration economies or of a systematically increasing failure of smaller cities to use best-practice technology. In either case, the results imply that urbanization may have an important positive influence on national economic growth.
\end{abstract}

\section{INTRODUCTION}

The resurgence of interest in economic growth has increased the importance of understanding the differences in productivity among the manufacturing sectors of cities and regions. These differences are well documented for many countries, including Brazil, Japan, Sweden, and the United States; econometric studies find that agglomeration economies-localization or urbanization economies-are important determinants of these differences ( $\AA$ berg 1973; Henderson 1988; Moomaw 1983a, 1988; and Nakamura 1985). Not only are agglomeration economies important to the theories of firm location and city-size distribution (Henderson 1988; Moomaw 1981; and Yezer and Goldfarb 1978), they are attracting more attention because they provide a possible explanation of economy-wide increasing returns and thus endogenous growth (e.g., Krugman 1991; and Glaeser et al. 1992).

Econometric estimates of the determinants of productivity differences and the importance of agglomeration economies typically have relied on estimating an "average" production function. Beeson and Husted $(1989,15)$, however, use

... a stochastic frontier production-function model . . . to measure and compare productive efficiency in the manufacturing sector across states in the United States. ... (The) approach estimates the properties of the "best-practiced" technology. The inefficiency or relative productivity of a state's manufacturing sector is then

\footnotetext{
*Assistant Professor of Economics, Central Missouri State University, and Professor of Economics, Oklahoma State University at Stillwater, respectively.
} 
measured in terms of that state's average deviation from this "best practice" frontier.

The concepts of best-practice technologies and the distance that particular regions or countries are from best practice are important parts of the study of convergence in productivity growth among nations and, presumably, regions. For instance, convergence to best practice may be an important explanation of the rapid growth of several East Asian countries (World Bank 1993).

This paper uses stochastic frontier techniques to derive efficiency (relative productivity) measures for 50 Canadian cities. To our knowledge, it is the first to use frontier techniques to analyze city productive efficiency, as opposed to state or regional, and the first to examine the determinants of productivity differences among Canadian cities. We use specifications derived from the Cobb-Douglas production function and the Constant-Elasticity-of-Substitution (CES) production function to estimate efficiency frontiers. We use each frontier to compute an efficiency measure; then we estimate the determinants of efficiency. ${ }^{1}$

The study's main purpose is to provide information about the determinants of productivity differences among Canadian cities. It examines the importance of agglomeration economies and puts its findings for Canada in context with findings for other countries. A secondary purpose is to show that stochastic frontier techniques provide important information about productivity and cities. Finally, it speculates about the importance of our results for the general economic growth conversation.

\section{DERIVATION OF THE EFFICIENCY INDICES}

In theory, a production function gives the maximum output from a given input combination. But production functions typically are estimated with a twosided error term, which gives an "average" rather than a "best practice" production function. Estimating a production frontier with a one-sided rather than a two-sided error term yields a "best practice" frontier. The distance that the output of a given city is from the frontier measures the city's (in)efficiency.

We estimate a stochastic frontier with panel data for $T$ years for $N$ cities (see Beeson and Husted 1989, and Schmidt and Sickles 1984, for detailed discussions of the approach). Technical inefficiency (the ratio of minimum-possible input usage to actual input usage) can be estimated consistently with panel data. This is so because adding more observations on the same city yields information that cannot be attained by adding more cities to a single cross section; thus, panel data are ideal for estimating frontiers. Using panel data also makes it unnecessary to make 
the strong distributional assumptions required about error terms when using a single cross section of data to estimate a frontier. Furthermore, consistent estimates of inefficiency with panel data do not require that the one-sided error term be uncorrelated with the regressors, which is another advantage over using a single cross section. ${ }^{2}$

The model estimated with panel data can be expressed as

$$
\begin{aligned}
& Y_{i t}=a+B X_{i t}+v_{i t}-u_{i}, \\
& i=1, \ldots, N \quad t=1, \ldots, T
\end{aligned}
$$

where $t$ indicates the year; $i$ indicates the city; $Y_{i t}$ is output; $X_{i t}$ is a vector of inputs; $v_{i t}$, is the two-sided error term (assumed to be independent of $X_{i t}$ ) that captures statistical "noise" and exogenous shocks; and $u_{i}\left(u_{i} \geq 0\right)$ is the one-sided error term that captures technical inefficiency. It is assumed that the $u_{i}$ are independently and identically distributed with mean $U$ and variance $\sigma_{v}^{2}$. It is also assumed that the $u_{i}$ are independent of the $v_{i t}$.

Depending upon the assumptions, this model may be estimated with the generalized- least-squares (error-components) or the within (dummy-variable) estimator. ${ }^{3}$ We assume that the $u_{i}$ are fixed and use the dummy-variable estimator to derive a separate intercept for each of the $N$ cities. Consistency does not require independence between the $u_{i}$ and $X_{i p}$ nor does it require a specification of the distribution of $u_{i}$.

This estimate of inefficiency $\left(u_{i}\right)$ is obtained from estimates of the $N$ intercepts, $a_{i}$. Let $a=\max \left(a_{i}\right)$. Then the inefficiency of a particular city is $u_{i}=a-a_{i}$, $i=1, \ldots, N$. The efficiency index

$$
E F F=100 e^{-u i}
$$

assumes that the most efficient city is 100 percent efficient. ${ }^{4}$

Problems with this estimator may arise in computing standard errors or confidence intervals; this is not a problem, however, if, as here, $N$ is large compared with $T$. We assume that the inefficiency of each city is constant over time. This assumption is not inherent in the stochastic frontier methodology. Cornwell, Schmidt and Sickles (1990), for instance, estimate time-varying inefficiencies for each cross-sectional unit. Their study uses quarterly data for firms over 11 years. Our sample covers only five years, and our cross-sectional units are cities, rather than firms. The efficiency characteristics of cities would not be expected to change as fast as those of firms. Consequently, the assumption of a constant inefficiency for each city is appropriate here. ${ }^{5}$ 
We also assume that operating inside the best-practice frontier is the only way that the one-sided error term $\left(u_{i}\right)$ can be greater than zero. This assumes that each city has access to the identical technology. Because our study deals with aggregate manufacturing, different cities with different industry mixes will not have access to the same technology. Although this is not a measure of pure technical inefficiency, we follow the literature in referring to it as such. ${ }^{6}$

\section{EMPIRICAL RESULTS}

We use two stochastic frontiers-one from the Cobb-Douglas production function and one from the CES production function-to estimate the efficiency of manufacturing in Canadian cities. We have data for 50 cities from Statistics Canada. Manufacturing data for 1976-1980 come from the Census of Manufacturing and Primary Industries. Other data come from the 1981 Census of Canada.

The Cobb-Douglas frontier in natural logarithms is

$$
\begin{aligned}
\operatorname{LnY} Y_{i t}= & a_{i}+B_{1} L_{n} L_{i t}+B_{2} \operatorname{LnK} K_{i t}+D_{1}+D_{2}+D_{3}+D_{4}+v_{i t}+u_{i}, \\
& (i=1, \ldots, 50 ; t=1, \ldots, 5)
\end{aligned}
$$

where $Y_{i t}$ is the value added in manufacturing; $L_{i t}$ is the man hours used in the manufacturing sector; $K_{i t}$ is the capital employed in the manufacturing-all for city $i$ in year $t ; D_{1}-D_{4}$ are dummy variables for the 1977-1980; $v_{i t}$ is the two-sided error term representing both statistical "noise" and exogenous shocks occurring in city $i$ in year $t$; and $u_{i}$ is the one-sided error term representing the technical inefficiency associated with city $i$. We proxy capital-stock, $K_{i t}$, by value added minus total wages. ${ }^{7}$ The dummy variables $D_{1}-D_{4}$ are intended to capture the effect of price and productivity changes over time.

Table 1 presents the estimates of the Cobb Douglas frontier. The coefficients of labor and capital show that these inputs are, positive as expected; their sum, 0.66 , shows decreasing returns to scale. The coefficient of labor-labor's share-is too small. Each successive coefficient of a time dummy is larger, reflecting inflation and neutral technical change over time. Each city intercept is positive; a city intercept may be interpreted as follows. Given some level of inputs, the greater the intercept, the greater the manufacturing output in that city. Given two cities with the same quantity of inputs, the city with the larger intercept is more efficient. As Table 1 shows, all coefficients are significant at the .01 level.

Following Dhrymes (1965), we also estimate an equation derived from a CES production function. We do this for two reasons: First, we believe that it gives us additional information; failure to find qualitatively different results 
TABLE 1

The Estimate of the Cobb-Douglas Frontier

\begin{tabular}{|c|c|c|c|c|c|c|c|}
\hline Parameter & Estimate & T Stat & $\mathrm{PR}>\mathrm{T}$ & Parameter & Estimate & T Stat & $\mathrm{PR}>\mathrm{T}$ \\
\hline Calgary & 5.3744 & 13.88 & 0.0001 & St. Hyanchinthe & 4.4702 & 14.10 & 0.0001 \\
\hline Chicoutimi & 5.2387 & 14.51 & 0.0001 & St. Jean & 4.8756 & 13.99 & 0.0001 \\
\hline Edmonton & 5.5610 & 13.88 & 0.0001 & St. Jerome & 4.7045 & 14.18 & 0.0001 \\
\hline Halifax & 4.8934 & 13.84 & 0.0001 & Sarina & 5.5456 & 14.75 & 0.0001 \\
\hline Hamilton & 5.8235 & 13.58 & 0.0001 & Shawnigan & 5.0338 & 14.45 & 0.0001 \\
\hline Kitchner & 5.5849 & 13.45 & 0.0001 & Sherbrooke & 4.9881 & 14.08 & 0.0001 \\
\hline London & 5.4073 & 13.88 & 0.0001 & Sore & 5.1061 & 14.42 & 0.0001 \\
\hline Montreal & 6.1640 & 12.98 & 0.0001 & Sydney & 5.1189 & 16.20 & 0.0001 \\
\hline Ottawa-Hull & 5.3019 & 13.86 & 0.0001 & Trenton & 4.7498 & 14.30 & 0.0001 \\
\hline Quebec & 5.3462 & 13.78 & 0.0001 & Trois Riviers & 5.1164 & 14.07 & 0.0001 \\
\hline Regina & 4.9747 & 14.44 & 0.0001 & Truro & 4.4265 & 14.33 & 0.0001 \\
\hline St. John & 5.0707 & 14.42 & 0.0001 & Valleyfield & 4.7353 & 14.45 & 0.0001 \\
\hline Saskatoon & 4.8545 & 14.30 & 0.0001 & Victoriaville & 4.6237 & 14.22 & 0.0001 \\
\hline St. Catherines & 5.6410 & 13.79 & 0.0001 & Barrie & 4.8290 & 14.43 & 0.0001 \\
\hline St. John's & 4.6695 & 14.52 & 0.0001 & Brockville & 4.8954 & 14.51 & 0.0001 \\
\hline Sudbury & 5.0782 & 14.66 & 0.0001 & Cobourg & 4.8330 & 15.01 & 0.0001 \\
\hline Thunder Bay & 5.1239 & 14.34 & 0.0001 & Drummondville & 4.8445 & 14.05 & 0.0001 \\
\hline Toronto & 6.2711 & 12.96 & 0.0001 & Granby & 4.8001 & 13.95 & 0.0001 \\
\hline Victoria & 4.9457 & 14.75 & 0.0001 & Midland & 4.6735 & 14.39 & 0.0001 \\
\hline Windsor & 5.6285 & 13.87 & 0.0001 & New Glasgow & 4.4771 & 15.04 & 0.0001 \\
\hline Winnipeg & 5.5009 & 13.41 & 0.0001 & Peterborough & 5.1191 & 14.29 & 0.0001 \\
\hline Brantford & 5.2765 & 13.93 & 0.0001 & Vancouver & 5.8368 & 13.60 & 0.0001 \\
\hline Charolettetown & 4.2474 & 15.15 & 0.0001 & $\operatorname{LnL}$ & 0.2731 & 8.11 & 0.0001 \\
\hline Guelph & 5.1706 & 14.08 & 0.0001 & $\operatorname{Ln} K$ & 0.3910 & 21.24 & 0.0001 \\
\hline Joliette & 4.6346 & 14.39 & 0.0001 & $D_{1}$ & 0.0603 & 5.15 & 0.0001 \\
\hline Kingston & 4.9717 & 14.50 & 0.0001 & $D_{2}$ & 0.1356 & 10.86 & 0.0001 \\
\hline Medicine Hat & 4.8113 & 15.26 & 0.0001 & $D_{3}$ & 0.1931 & 11.61 & 0.0001 \\
\hline Moncton & 4.4774 & 14.58 & 0.0001 & $D_{4}$ & 0.2645 & 13.10 & 0.0001 \\
\hline
\end{tabular}

$R^{2}=0.9998$

would increase confidence in the results. Second, we recognize that some people are skeptical about the proxy we use for capital. By estimating the demand-forlabor equation from the CES production function, we do not need a capital variable. The CES frontier function in natural logarithms is

$$
L n W_{i t}=a_{i}+B_{1} \operatorname{Ln} Y_{i t}+B_{2} \operatorname{Ln} L_{i t}+D_{1}+D_{2}+D_{3}+D_{4}+v_{i t}+u_{i}
$$

where, except for $W_{i t}$ (the wage per man hour in city $i$ in year $t$ ), all variables are defined above.

Table 1 shows that the coefficients of all the dummy variables are significant and positive. The coefficient of output is 0.28 , and the coefficient of labor is -0.68 ; these coefficients have the expected sign. Carlino (1978) provides a formula that shows that these coefficients imply decreasing returns to scale: the return to scale parameter is 0.44 . To interpret the coefficients of the city dummies, imagine two cities, identical, except that one has a larger intercept. Wages are higher in that city, implying in a neoclassical model that the marginal product of 
labor is also higher. ${ }^{8}$ The city with the larger intercept is more efficient or productive. (To conserve space, we discuss, but do not provide, the detailed results of this estimate. Details available upon request). ${ }^{9}$

We construct the index of efficiency using equation (2), and report the results for both models in Table 2. An examination of the table shows that the index of efficiency is essentially the same for both models. The simple correlation between the two measures is 0.987 . The index from both models falls off quickly from 100 percent. Most cities have indices with values between 20 and 40 percent. The CES-derived index generally has lower values than the other, with the lowest CES value being 8.2 percent, compared to 13.2 for the lowest Cobb-Douglas value.

\section{AGGLOMERATION ECONOMIES AND THE EFFICIENCY INDICES}

This study's main purpose is to increase understanding about the effects of urbanization-city size-on productivity or efficiency. We do so by examining the effects of city size and other variables on the efficiency indices.

Agglomeration economies may exist because firms in a larger city have access to a larger pool of skilled labor, entrepreneurial talent, wholesalers of specialized items, and specialized business services. Firms, therefore, can contract with independent suppliers for specialized goods and services rather than produce the goods and services themselves. The greater division of labor in these specialized firms allows them to supply these items at costs lower than those of unspecialized firms (Evans, 1972; Moomaw, 1983a).

Differences in the use of best-practice technology provide another source of productivity differences among cities. Carlino $(1978,27)$ argues that large cities are more apt to use best practice. He expects that innovations originate in the largest cities and, through spatial diffusion, are transmitted down the urban hierarchy. A related argument is that firms that are the most successful in adopting technological changes are those exposed to many stimuli, which are more prevalent in large cities. Just as with agglomeration economies, these arguments suggest that larger cities will be more productive or efficient. Plausible arguments, however, can be made that size is detrimental to efficiency. For instance, criminal activity may create more problems in large cities. City population, $P O P$, measures size.

Although size may be beneficial, congestion can raise costs and reduce efficiency. On the other hand, some of the positive effects of size on productivity are enhanced by greater density or congestion. Population density, POPDEN, is our measure of congestion. Our discussion allows for either a positive or negative sign for POP and POPDEN; consequently, two-tailed hypothesis-testing is ap- 
TABLE 2

Efficiency Rankings for Canadian Cities

\begin{tabular}{|c|c|c|c|c|}
\hline \multicolumn{2}{|c|}{ Cobb-Douglas } & \multirow[b]{2}{*}{ Rank } & \multicolumn{2}{|l|}{ CES } \\
\hline City & $\mathrm{EFF}$ & & City & EFF \\
\hline Toronto & $100.000 \%$ & 1 & Toronto & $100.000 \%$ \\
\hline Montreal & 89.846 & 2 & Montreal & 88.547 \\
\hline Vancouver & 64.776 & 3 & Vancouver & 63.193 \\
\hline Hamilton & 63.919 & 4 & Hamilton & 59.255 \\
\hline St. Catherines & 53.258 & 5 & St. Catherines & 49.022 \\
\hline Windsor & 52.596 & 6 & Kitchner & 46.814 \\
\hline Kitchner & 50.352 & 7 & Windsor & 46.809 \\
\hline Sarina & 48.408 & 8 & Winnipeg & 41.533 \\
\hline Edmonton & 48.231 & 9 & Edmonton & 39.590 \\
\hline Winnipeg & 46.293 & 10 & Calgary & 35.524 \\
\hline London & 42.159 & 11 & London & 34.734 \\
\hline Calgary & 41.618 & 12 & Ottawa-Hull & 32.970 \\
\hline Quebec & 39.660 & 13 & Brantford & 31.859 \\
\hline Ottawa-Hull & 37.939 & 14 & Quebec & 30.800 \\
\hline Brantford & 36.989 & 15 & Chicoutimi & 30.284 \\
\hline Chicoutimi & 35.618 & 16 & Sarina & 29.759 \\
\hline Guelph & 33.273 & 17 & Sudbury & 27.822 \\
\hline Thunder Bay & 31.754 & 18 & Peterborough & 27.042 \\
\hline Peterborough & 31.603 & 19 & Sorel & 26.988 \\
\hline Sydney & 31.595 & 20 & Trois Riviers & 26.051 \\
\hline Trois Riviers & 31.518 & 21 & Guelph & 23.978 \\
\hline Sorel & 31.194 & 22 & Thunder Bay & 23.651 \\
\hline Sudbury & 30.337 & 23 & Victoria & 23.317 \\
\hline St. John & 30.109 & 24 & St. John & 22.516 \\
\hline Shawnigan & 29.018 & 25 & Regina & 21.926 \\
\hline Sherbrooke & 27.721 & 26 & Sherbrooke & 21.840 \\
\hline Regina & 27.354 & 27 & Sydney & 21.659 \\
\hline Kingston & 27.272 & 28 & Shawnigan & 20.556 \\
\hline Victoria & 26.572 & 29 & Kingston & 20.384 \\
\hline Valleyfield & 26.296 & 30 & St. Jean & 19.086 \\
\hline Brockville & 25.267 & 31 & Saskatoon & 18.849 \\
\hline Halifax & 25.216 & 32 & Drummondville & 18.656 \\
\hline St. Jean & 24.773 & 33 & Granby & 18.647 \\
\hline Saskatoon & 24.254 & 34 & Halifax & 18.110 \\
\hline Cobourg & 24.219 & 35 & Valleyfield & 17.673 \\
\hline Drummondville & 24.014 & 36 & Barrie & 17.388 \\
\hline Barrie & 23.645 & 37 & Brockville & 17.176 \\
\hline Medicine Hat & 23.230 & 38 & St. Jerome & 16.731 \\
\hline Granby & 22.977 & 39 & St. Hyanchinthe & 15.996 \\
\hline Trenton & 21.844 & 40 & Joliette & 15.446 \\
\hline St. John's & 21.159 & 41 & St. John's & 15.342 \\
\hline St. Jerome & 20.876 & 42 & Trenton & 15.169 \\
\hline St. Hyanchinthe & 20.831 & 43 & Victoriaville & 14.833 \\
\hline Midland & 20.239 & 44 & Midland & 14.778 \\
\hline Joliette & 19.446 & 45 & Cobourg & 13.574 \\
\hline Victoriaville & 19.256 & 46 & New Glasgow & 13.192 \\
\hline Moncton & 16.636 & 47 & Moncton & 12.767 \\
\hline New Glasgow & 16.631 & 48 & Medicine Hat & 12.551 \\
\hline Truro & 15.810 & 49 & Truro & 11.325 \\
\hline Charolettetown & 13.217 & 50 & Charolettetown & 8.247 \\
\hline
\end{tabular}


propriate. (We did, nevertheless, anticipate a positive effect for $P O P$ and a negative effect for POPDEN.)

Unbiased estimates of the coefficients of size and density require the control of factors that both affect efficiency and are correlated with city population or density. We believe that the two most important factors to control are the quality of the labor force and industry mix. The percentage of the adult population with a secondary education certificate, $E D$, is the control for labor quality. No other controls for labor quality were available.

Data limitations also prevented the construction of direct measures of industry mix for the manufacturing sectors of Canadian cities. Two variables available are the percent of manufacturing labor force that is male, $M L F$, and the city's unemployment rate, $U R$. Both variables vary with industry mix. Although the gender composition of the labor force is known to vary with industry mix, a city's unemployment rate does not have the same obvious relationship to industry mix. Think, however, of a city's unemployment rate as the weighted average of industry unemployment rates. If the unemployment rate for an industry is the same in all cities, then variations in city unemployment rates must be based on different weights (different industry mix) in different cities. ${ }^{10}$

In short, we regress the efficiency index ( $L n E F F)$ on several explanatory variables. The model with variables in natural logarithms is

$L n E F F=B_{0}+B_{1} L n P O P+B_{2} L n M L F+B_{3} L n E D U C+B_{4} L n U R+B_{5} L n P O P D E N+u(5)$

where $P O P$ is the city population; $M L F$ is the percent of the manufacturing labor force that is male; $E D$ is the percent of the population with a secondary certificate; $U R$ is the city's unemployment rate; POPDEN is the population density of the city; and $u$ is a random error term.

This equation has some similarity to that used by Beeson and Husted. ${ }^{11}$ They have education, unionization, industry mix, and urbanization variables. Although we include education, unionization data were not available to us. Moreover, our industry-mix controls are crude; theirs are well defined.

Table 3 presents the results of this regression. The $R^{2}$ s show that the regressions have satisfactory explanatory power. The three variables of most interest are LnPOP, LnPOPDEN, and LnEDUC: population, population density, and education. Population has a clear positive association with efficiency (productivity). Surprisingly, because one might expect it to capture negative congestion effects, population density also positively affects efficiency in both equations and is significant in the CES version. Education too has a positive effect; it is significant at the 0.10 level in both equations. ${ }^{12}$ The unemployment rate and the percentage of 
TABLE 3

Determinants of the Efficiency Indices: No Regional Effects

\begin{tabular}{lccccc}
\hline & \multicolumn{2}{c}{ Cobb-Douglas } & & \multicolumn{2}{c}{ CES } \\
\cline { 2 - 3 } \cline { 5 - 6 } Variables & \multicolumn{2}{c}{} & & & \\
\cline { 3 - 6 } Intercept & 1.2691 & 2.683 & & 0.3723 & 0.738 \\
LnPOP & 0.2958 & $8.285^{* * *}$ & & 0.3560 & $9.231^{* * *}$ \\
LnMLF & 3.3980 & $3.261^{* * *}$ & & 3.9200 & $3.525^{* * *}$ \\
LnEDUC & 0.1891 & $1.774^{* *}$ & & 0.1865 & $1.640^{*}$ \\
LnUR & -0.2415 & $-2.194^{* *}$ & & -0.2262 & $-1.962^{*}$ \\
LnPOPDEN & 0.0599 & 1.537 & & 0.1108 & 2.662 \\
$R^{2}=0.7435$ & & & $R^{2}=0.8020$ & \\
\hline
\end{tabular}

***, **, and * indicate significance at $0.01,0.05$, and 0.10 . Significance of $\operatorname{LnEDUC}$ based on a 1-tail test; other variables based on 2-tail.

males in the manufacturing labor force also are significant. As previously stated, these variables control industry mix, among other things.

Our results are similar to those of Beeson and Husted in that education is significant in both studies, as are other control variables. The results on urbanization differ. They find that the percentage of a state's population in metropolitan areas has a positive effect on efficiency and that the total metropolitan population of a state has a negative effect. Although the current study deals with metropolitan areas rather than states, both of its measures of urbanization-size and densityhave positive effects.

Differences among Canadian provinces are pronounced. To explore the possibility that coefficients for city size and density are confounded with regional effects, we estimate these equations augmented with four regional dummy variables. The eastern provinces, $E P$, of Canada, form one distinct group. These provinces-New Brunswick, Newfoundland, Nova Scotia, and Prince Edward Island, on the periphery of the national economy, have relatively low income per capita. British Columbia, $B C$, is also remote, but it is a high-income province. Ontario, $O N T$, is the manufacturing center of the Canadian economy. Quebec, $Q U E$, is sui generis, but has established manufacturing. The prairie provinces, Alberta, Manitoba, and Saskatchewan, rely heavily on agriculture and natural resources. They define the omitted dummy variable.

According to Table 4, location in Ontario has a positive effect on efficiency. Location in Quebec has a positive effect as well, but it is significant only in the CES version. The positive effect of this "manufacturing belt" location contradicts the Beeson and Husted finding about the manufacturing belt in the United States. The coefficients of the other regional dummies are not significant. 
TABLE 4

Determinants of the Efficiency Indices: Regional Effects Included

\begin{tabular}{|c|c|c|c|c|}
\hline \multirow[b]{2}{*}{ Variables } & \multicolumn{2}{|c|}{ Cobb-Douglas } & \multicolumn{2}{|c|}{ CES } \\
\hline & Estimate & T Stat & Estimate & T Sta \\
\hline Intercept & 0.6351 & 1.022 & -0.6238 & -1.008 \\
\hline $\operatorname{LnPOP}$ & $0.2966^{* * *}$ & 10.430 & $0.3588^{* * *}$ & 12.672 \\
\hline$L n M L F$ & $3.3482^{* * *}$ & 4.106 & $3.3977^{* * *}$ & 4.771 \\
\hline LnEDUC & -0.1376 & -0.991 & -0.1914 & -1.385 \\
\hline LnUR & -0.1286 & -0.985 & -0.1760 & -1.355 \\
\hline LnPOPDEN & $0.5796^{*}$ & 1.710 & $0.1029^{* * *}$ & 3.049 \\
\hline$E P$ & -0.0914 & -0.703 & -0.0072 & -0.055 \\
\hline$B C$ & -0.0423 & -0.265 & 0.0409 & 0.258 \\
\hline$O N T$ & $0.3558^{* * *}$ & 3.820 & $0.4629^{* * *}$ & 4.992 \\
\hline $\begin{array}{l}\text { QUE } \\
R^{2}=0.8422\end{array}$ & 0.2144 & 1.393 & $\begin{array}{c}0.3590^{* * *} \\
R^{2}=0.8940\end{array}$ & 2.342 \\
\hline
\end{tabular}

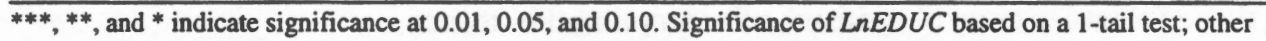
variables based on 2-tail.

The critical finding is that the coefficients of the agglomeration variablespopulation and population density-are robust. They are essentially unchanged in the new regression; their $\mathrm{t}$-values increase, indicating a more precise estimate. The coefficients of both education and unemployment lose significance, suggesting that these variables and the regional dummies control similar factors. Finally, the results for the percentage of males in the labor force are essentially unchanged.

\section{v. CONCLUSION}

This paper has studied the efficiency of manufacturing in Canadian cities, using a stochastic production frontier. The panel data set eliminates many econometric problems associated with estimating such a frontier because adding information on the same observation yields information that is not attainable by simply adding more observations to a single cross section.

We estimated frontiers using both Cobb-Douglas and CES production functions and calculated efficiency indices for each of the 50 cities. Then we used regression analysis to explain their variation. In general, the analysis shows that just as in Brazil, Japan, the United States, and other countries studied, city size has a positive effect on productivity. In specific, the determinants of the efficiency 
index are similar to those found by Beeson and Husted (1989). The major difference is that they find an adverse effect on efficiency of metropolitan population in a state, whereas both of our urbanization variables have positive effects on efficiency.

Both city population and population density have strong effects on efficiency (productivity) in Canadian cities, supporting the proposition that large cities use best-practice technologies. Perhaps the large cities take advantage of static agglomeration economies-specialization and division of labor and so on. Smaller cities cannot do so because the relevant markets for labor or intermediate goods are not large enough. Strictly speaking, this is not an example of inefficiency or failure to use best practice; the technology is simply not available to smaller cities. Or perhaps innovative best practices are more likely to be developed and adopted in large cities because of the large number of interactions-knowledge spillovers-that occur there.

The fact that large cities are more likely to use best-practice technology suggests that urbanization would promote national economic growth both through innovation and diffusion of innovations. Although tentative, this suggestion hints at a fruitful area for further research.

\section{ENDNOTES}

1. We thank Rudy Greer, Andreas Savvides, and three anonymous reviewers for helpful comments. They deserve much credit for the refinement of this paper; any remaining shortcomings are our responsibility.

2. Forsund et al. (1980 p. 7) explain that a deterministic frontier estimate can be obtained with a single cross section. Obtaining an estimate requires a choice of a distribution for the error term, but there is no obvious "correct" distribution. It also assumes that all variations in performance arise from factors that the crosssection unit controls (inefficiency). Exogenous shocks that affect performance (weather, exchange rate fluctuations, etc.) are included-inappropriately-in inefficiency in the deterministic approach.

3. We choose the dummy-variable rather than the error-components estimator, because the sample of Canadian cities can be regarded as the population, rather than a random sample from a larger population of cities. Therefore, the conditional inference permitted by the dummy-variable estimator is more appropriate than the unconditional inference that could be made with the error-components estimator. As previously noted, the former estimator does not require that a distribution be assumed for the one-sided error term (see Judge et al. 1988, 489491). 
4. This is a strong assumption, but true as the number of cross-section units goes to infinity (Beeson and Husted 1989; Schmidt and Sickles 1984). Moreover, it is used only to create an efficiency index. If one loosely interprets the efficiency index as relating to the most efficient city rather than to absolute efficiency, the assumption does not seem so stringent.

5. Battese and Coelli (1988) recognize that the assumption of constant inefficiency over time can be troublesome. They do not think it is a problem with a short time period.

6. We follow Beeson and Husted (1989, $17 \mathrm{fn}$. 4), who note this problem and continue to use the inefficiency terminology. As a result of this problem, it is important to include measures of industry mix in the equation explaining differences in technical efficiency.

7. This proxy was used by Åberg (1973) and by Moomaw (1981) for cities and regions in Sweden and the United States, respectively. Miller (1983) criticizes, and Moomaw (1983b) defends the proxy. Because the use of this proxy is not universally accepted, we also use a specification derived from the CES production function that does not require data on capital stock or services.

8. Profit maximization and labor mobility lead to a correspondence between wages and marginal products. As one reviewer pointed out, these assumptions are common in research of this type, but increasing returns and dual labor markets may make the interpretation suspect. Research dealing with these issues might be fruitful.

9. The CES and Cobb-Douglas results imply decreasing returns to scale of about the same magnitude. Beeson and Husted (1989), on the other hand, find mild increasing returns. They also find a more plausible labor's share: about 0.75 . Their fixed-effect results show that this assumption does not imply either decreasing returns to scale or a small share for labor. Although our proxy for capital may have distorted our Cobb-Douglas results, it is not a factor in the CES results. Beeson and Husted use the translog production function, a flexible functional form, to derive their estimates. This may account for the different results. We chose not to use a flexible functional form because we do believe that our capital proxy is appropriate for such use.

10. We do not pretend that this industry mix argument gives an acceptable theory of differences in unemployment rates among cities. We simply argue that the unemployment rate will be related to industry mix and can be used to control it. McGee (1985) provides empirical support for the importance of industry mix for state unemployment rates.

11. We use a log-linear specification because numerous studies have shown that the relationship between productivity and city size is nonlinear. No other specifications were tried. Although we had the Beeson and Husted study (1989) 
available when we specified equation (5), we were unable to specify a comparable equation for two reasons. First, their urbanization variables attempt to measure a state's urbanization rather than describe a city. In our sample, the percent of a state's population in metropolitan areas has no analogue. Furthermore, we did not have the data necessary to construct their industry mix variables.

12. Hypotheses on the coefficient of education are tested with one-tail tests because we can think of no plausible reason for education to have a negative effect on efficiency. In our judgment, to use a two-tail test in this circumstance would be inappropriate.

\section{REFERENCES}

Åberg, Y. "Regional Productivity Differences in Swedish Manufacturing." Regional and Urban Economics 3 (1973): 131-156.

Battese, G. E., and T. J. Coelli. "Prediction of Firm-Level Technical Efficiencies with a Generalized Frontier Production Function and Panel Data." Journal of Econometrics 38 (1988): 387-399.

Beeson, P., and S. Husted. "Patterns and Determinants of Productive Efficiency in State Manufacturing." Journal of Regional Science 29 (1989): 15-28.

Carlino, G. Economies of Scale in Manufacturing and Location. Netherlands: Intercontinental Graphics, 1978.

Cornwell, C., P. Schmidt, and R. C. Sickles. "Production Frontiers with CrossSectional and Time-Series Variation in Efficiency Levels." Journal of Econometrics 46 (1991): 185-200.

Dhrymes, P.J. "Some Extensions and Tests for the CES Class of Production Functions." The Review of Economics and Statistics 47 (1965): 357-366.

Evans, A.W. "The Pure Theory of City Size in an Industrial Economy." Urban Studies 9 (1972): 49-77.

Forsund, F.R., and L. Hjalmarsson. "On the Measurement of Productive Efficiency," The Swedish Journal of Economics 76 (1974): 141-153.

Forsund, F.R., C.A. Lovely, and P. Schmidt. "A Survey of Frontier Production Functions and of Their Relationship to Efficiency Measurement." Journal of Econometrics 13 (1980): 5-25.

Glaeser, E., H. Call, J. Scheinkman, and A. Shiefer. "Growth in Cities." Journal of Political Economy 100 (1992): 1126-52.

Henderson, J.V. Urban Economic Development. New York: Oxford University Press, 1988. 
Judge, G. J., R. C. Hill, W. E. Griffiths, H. Lutkepohl, and T. C. Lee. Introduction to the Theory and Practice of Econometrics, 2nd ed. New York: John Wiley \& Sons, 1988: 468-496.

Krugman, P. "Increasing Returns and Economic Geography." Journal of Political Economy 99 (1991): 483-99.

Miller, E.M. "Productive Efficiency and Region: Comment." Southern Economic Journal 50 (1983): 257-260.

Moomaw, R.L. "Productivity and City Size: A Critique of the Evidence." Quarterly Journal of Economics 94 (1981): 675-688.

Moomaw, R.L. "Spatial Productivity Variations in Manufacturing: A Critical Survey of Cross-Sectional Analysis." International Regional Science Review 8 (1983a): 1-22.

Moomaw, R.L. "Productive Efficiency and Region: Reply." Southern Economic Journal, 50 (1983b), 261-264.

Moomaw, R.L. "Agglomeration Economies: Urbanization or Localization?" Urban Studies 25 (1988): 150-161.

Nakamura, R. "Agglomeration Economies in Urban Manufacturing Industries: A Case of Japanese Cities." Journal of Urban Economics 17 (1985): 108-124.

Schmidt, P. "On the Statistical Estimation of Parametric Frontier Production Function." The Review of Economics and Statistics 2 (1976): 238-239.

Schmidt, P., and R. Sickles. "Production Functions and Panel Data." Journal of Business and Economic Statistics 2 (1984): 367-374.

World Bank. The East Asian Miracle: Economic Growth and Public Policy. New York: Oxford University Press, 1993.

Yezer, A., and R.S. Goldfarb. "An Indirect Test of Efficient City Sizes." Journal of Urban Economics 5 (1978): 46-65. 